\title{
The Role of the p53 Protein in Stem-Cell Biology and Epigenetic Regulation
}

\author{
Arnold J. Levine ${ }^{1,2}$, Anna M. Puzio-Kuter ${ }^{1,2}$, Chang S. Chan ${ }^{1,2}$, and Pierre Hainaut ${ }^{3}$ \\ ${ }^{1}$ Institute for Advanced Study, Princeton, New Jersey 08340 \\ ${ }^{2}$ Cancer Institute of New Jersey of Rutgers Medical School, New Brunswick, New Jersey 08903 \\ ${ }^{3}$ Grenoble Institute for Research on Cancer, Grenoble, France \\ Correspondence: alevine@ias.edu
}

The 553 protein plays a passive and an active role in stem cells. The transcriptional activities of p53 for cell-cycle arrest and DNA repair are largely turned off in stem cells, but there is some indication that long-term stem-cell viability may require other p53-regulated functions. When p53 is activated in stem cells, it stops cell division and promotes the commitment to a differentiation pathway and the formation of progenitor cells. In the absence of any p53 activity, stem-cell replication continues and mistakes in the normal epigenetic pathway occur at a higher probability. In the presence of a functionally active p53 protein, epigenetic stability is enforced and stem-cell replication is regulated by commitment to differentiation. Over a lifetime of an organism, stem-cell clones compete in a tissue niche for Darwinian replicative advantages and in doing so accumulate mutations that permit stem-cell replication. Mutations in the p53 gene give stem cells this advantage, increase the clonal stem-cell population, and lower the age at which cancers can occur. Li-Fraumeni patients that inherit p53 mutations develop tumors in a tissue-type-specific fashion at younger ages. Throughout the life of a Li-Fraumeni patient, the tumor types that arise occur in tissues where stem cells are active and cell division is most rapid. Thus, p53 mutations that are inherited or occur during developmental life act in stem cells of the mesenchymal and epithelial lineages, whereas p53 mutations that occur in progenitor or differentiated (somatic) cells later in life function in tissues of endodermal origins, indicating that p53 may function differently in different developmental lineages.

\section{DEFINITIONS AND CLASSIFICATION OF DIFFERENT TYPES OF STEM CELLS}

\section{Totipotent and Pluripotent Stem Cells}

$T_{c=1}^{\text {he }}$ he fertilized egg is the only totipotent stem cell producing all of the extraembryonic membranes, the germline, and somatic cells of the embryo. The fertilized egg divides rapidly, rolling in an epigenetic program that commonly produces a blastula in many diverse invertebrate and vertebrate organisms. In mammals, the blastula contains cells on the surface of the sphere that will produce extraembryonic membranes and, at a dorsal location, the inner cell mass cells, each one of which is capable of producing the germline and somatic cells and tis-

Editors: Guillermina Lozano and Arnold J. Levine

Additional Perspectives on The p53 Protein available at www.perspectivesinmedicine.org

Copyright (C) 2016 Cold Spring Harbor Laboratory Press; all rights reserved; doi: 10.1101/cshperspect.a026153

Cite this article as Cold Spring Harb Perspect Med 2015;6:a026153 
A.J. Levine et al.

sues of the embryo. The germline cells are segregated from the future somatic cells and at a later time in development they migrate from the yolk sac region into the genital ridge, which produces the testis or the ovaries. Transplantation experiments with genetically marked single inner cell mass cells placed into the inner cell mass of a different embryo have shown the ability of these pluripotent stem cells to contribute to all of the somatic and germline tissues of the body. Interestingly, although there are many inner cell mass cells in a blastula, one is sufficient to produce a normal embryo, so there is excellent homeostatic control over the size and proportion of an embryo and adult. The experiments of Gurdon and colleagues (Gurdon 1973) first showed that the nucleus from cells of a tadpole could be reprogrammed by serial passages through the cytoplasm of eggs, enabling those diploid nuclei to produce an entire organism after its transplantation into another enucleated egg. This showed that the egg cytoplasm contains activities that permit the epigenetic reprogramming of differentiated cell nuclei so as to produce many different cell and tissue types (although it was not understood in precisely those terms at the time). Later, Yamanaka and colleagues (Takahashi et al. 2007) showed that the introduction of four transcription factors, Myc, KLF-4, Oct-4, and Sox-2, into differentiated fibroblasts of mouse or human cells could result in the production of induced pluripotent stem (iPS) cells that were capable of contributing to most or all cell types and tissues of a mouse. The iPS cells are the rough equivalent of the inner cell mass cells. It is now clear that the epigenetic programming during development and deprograming of differentiated cells to produce a stem cell results from DNA modifications (in methylcytosine) and histone modifications (acetylation and deacetylation, methylation and demethylation, phosphorylation, ubiquitination, and sumoylation), which impact transcriptional regulation. Thus, the process of development proceeds by rolling in an epigenetic program in a stem cell and its progeny, which limits or enhances transcriptional capabilities and results in a differentiated cell type. Under normal circumstances, this epi- genetic program is quite stable but it is not irreversible. It can be altered by the experimental procedures described above and in some pathological conditions such as cancer.

\section{Tissue-Specific Stem Cells}

There are, however, additional types of stem cells. After tissue differentiation, each tissue harbors in some form a tissue-specific stem cell that permits some regeneration or wound healing to occur. The tissue-specific stem cells have been identified and studied in some detail in a selected number of tissue types. The first of these stem cells was the hematopoietic stem cell, which ultimately produces, over a lifetime, many different cell types in the blood and cell types that enter into and become part of several tissues. In mammals, this stem cell arises in the yolk sac and produces cells in the fetal liver eventually moving to the bone marrow. It produces several lineages of cell types over a lifetimeerythroid, myeloid, platelets, lymphoid, mast cells, natural killer cells, etc.,--found in the blood and in tissues such as the liver (Kupffer cells) and brain (oligodendrocyte). More recently, the tissue-specific stem cell that produces the lining of the colon has been identified (Barker et al. 2007, 2010). It resides in the crypt of the villi and has been identified as the "slim cell." This stem cell replicates symmetrically producing two stem cells. From a pool of stem cells, one cell differentiates producing several cell types that contribute to the formation of a villous filling the lumen of the colon. As cell division continues cells are pushed to the tip of a villous at which time they then die and are shed into the lumen of the colon. This process, from stem cell to death, takes place over a 4-day period repeating itself throughout life. In the skin, a stem cell has been identified (in the hair follicle) producing the epidermis with a turnover rate of 29-33 days (Tumbar et al. 2004). A liver-specific stem cell, residing in the bile duct cells, can regenerate liver tissue after a wound (Huch et al. 2013b, 2015). Stem cells for the pancreas (Huch et al. 2013a; Boj et al. 2015), breast (Petersen et al. 1992; Kao et al. 1995; Sun et al. 1999; Stingl et al. 2001), and prostate (Gao et al. 2014; Kar- 
thaus et al. 2014) tissue have all been identified recently. All of these tissue-specific stem cells have common signal transduction pathways, which help them to replicate symmetrically. This can be reproduced and observed in vivo (Gregorieff and Clevers 2010; Itzkovitz et al. 2012) and in vitro (Huch et al. 2013a,b, 2015; Boj et al. 2015).

It has been possible to culture these tissuespecific stem cells under special conditions in a matrigel-like substrate. They require for division and differentiation the Wnt ligand, and the stem cells express the Wnt pathway. The Wnt pathway is enhanced in its signaling by R-spondins and its G-linked coupled receptor, termed LGR-5 (Schuijers and Clevers 2012), on the stem-cell surface. The much enhanced WNT signaling results in cyclin $\mathrm{D}$ production and rapid cell division. The medium commonly requires an inhibitor of bone morphogenetic protein (BMP) called noggin and the matrigel complex of collagen and laminin, but different tissuespecific stem cells cultured under these conditions can optimally require different soluble components (Sato et al. 2009; Barker et al. 2010). Remarkably, normal tissue-specific stem cells cultured under these conditions produce organoids that contain multiple cell types found in the tissue and assembled into a histological organization similar to the normal tissue in vivo. In cell culture, it has been possible to follow the division of stem cells (which replicate symmetrically producing two identical stem cells) and, when cell division is stopped or limited, differentiation proceeds into several cell types produced by these tissues. Using these conditions, tissue-specific stem cells have been identified and proven to be the tissue-specific stem cells.

A common feature of all tissue-specific stem cells studied to date is that Wnt is the growth factor ligand used by these cells. The Wnt pathway induces the transcription of the R-spondin (there are three R-spondins) G-protein-linked receptor LGR5 (LGR4 and 6 are also R-spondin receptors). R-spondin enhances by 10 - to 100 fold the activity of the Wnt pathway. R-spondin accomplishes this by inhibiting two transmembrane E-3 ligases (Rnf43 and Znrf3) that normally degrade the Wnt receptors, termed
Frizzled. Wnt also induces the transcription of Rnf43/Znrf3, so in the absence of R-spondin/ LGR5 the Wnt pathway down-regulates itself, replication slows or stops, and differentiation can proceed (de Lau et al. 2014). This is the reason why the LGR-5 G-protein-linked receptor is critical to the identification of a tissuespecific stem cell. It has become the biomarker of choice when identifying a tissue-specific stem cell (see Fig. 1).

\section{Cancer-Derived Tissue-Specific Stem Cells}

Although the normal tissue-specific stem cell was being characterized as described above, the search for cancer-specific stem cells was in progress. It has been possible to use the same culture conditions (Wnt, R-spondin, etc.) to identify tissue-specific stem cells from cancerous tissue. This has been accomplished with colon, prostate, and pancreatic cancers (Sato et al. 2011; Karthaus et al. 2014; Boj et al. 2015). Some cancers are composed of highly differentiated tumors and these have well-differentiated organoids, whereas other cancers are composed of poorly differentiated cancers and organoids. This is simply a function of the combinations of mutations harbored by the tissue-specific cancer stem cells. Unlike normal organoids, however, most of the organoids produced by cancerous tissue-specific stem cells are histologically disorganized and resemble the tumor tissue. In addition, the organoids (and the tissue-specific stem cells) have a mutational profile that resembles the tumor when the DNA from the tumor and organoids are sequenced. The cancerous organoids still require high levels of Wnt signaling (and have LGR-5 as a biomarker) in cell culture. Thus, these cancer stem cells have many of the properties that normal tissue stem cells have but often harbor epigenetic changes and sets of mutations that can impact the cell cycle, metabolic alterations, genomic instability, epigenetic instability, and differentiation. These organoids will surely be useful for drug testing in vitro.

Over the past 5 years, there have been a large number of publications that claim to have identified biomarkers for cancer-tissue-specific stem 
A.J. Levine et al.

A

B
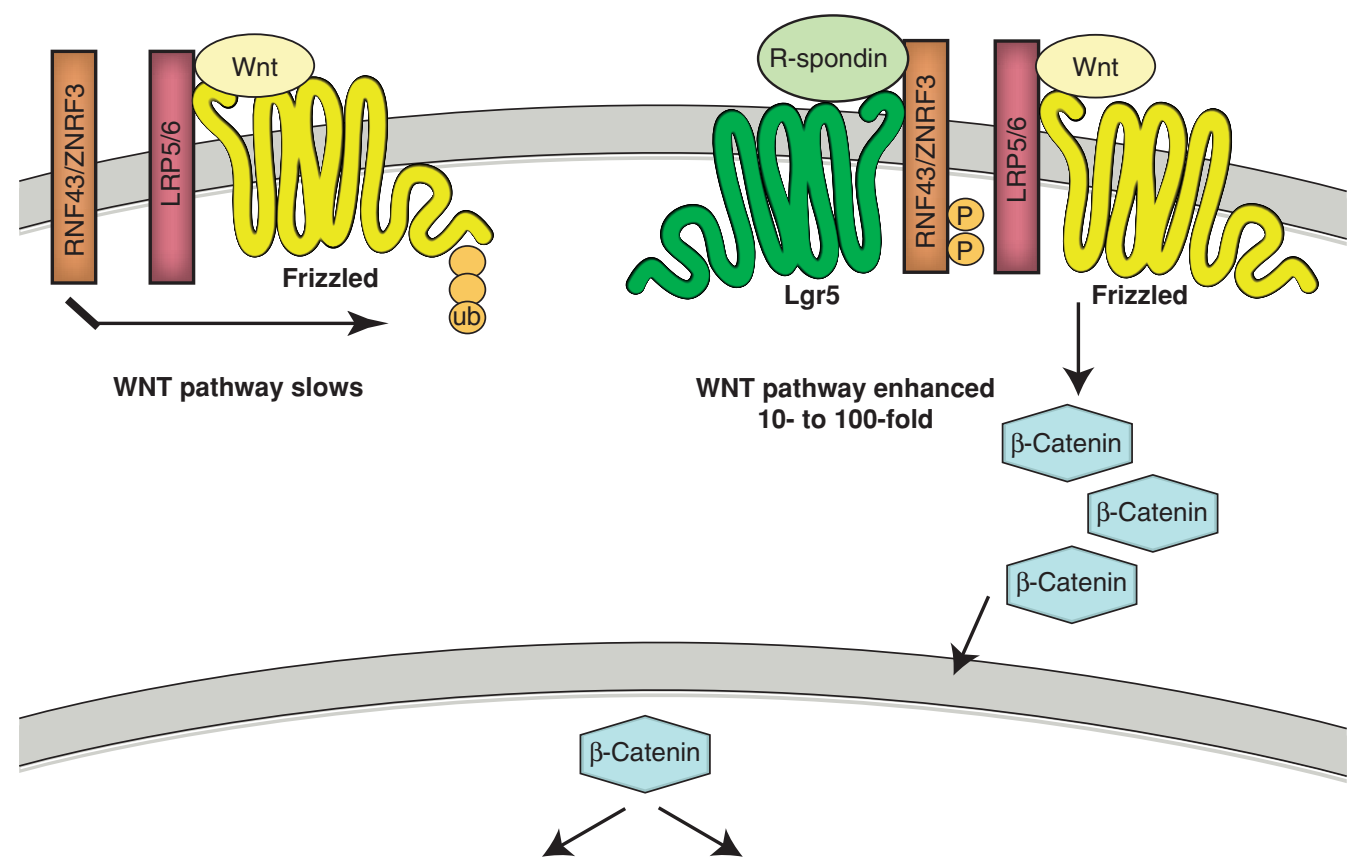

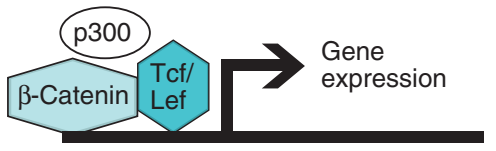

Promotes cell differentiation

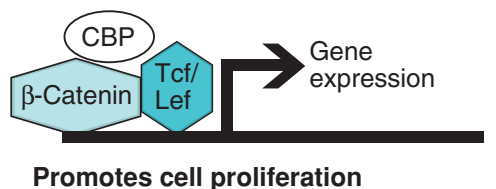

Promotes cell proliferation

Figure 1. WNT and R-spondin signaling. (A) ZNRF3/RNF43 ubiquitylates the WNT receptor Frizzled, thus slowing WNT signaling. $(B)$ When R-spondin is present, it binds to its receptor LGR5. This results in complex formation with ZNRF3/RNF43 allowing greater accumulation of Frizzled receptor on the plasma membrane and enhancement of WNT signaling.

cells. Based on the biomarkers, it has been possible to enrich for these stem cells and show that they are enriched for various properties associated with tumors such as tumorigenic potential in animals. The great majority of these biomarkers and stem cells are not related to the biomarkers observed for the Wnt and R-spondin pathways (like LGR5). Indeed, the cell culture conditions used in these studies of "so-called cancer stem cells" would inhibit the culture of LGR5-tissue-specific stem cells and the cancerous tissue-specific stem cells observed in organoids. Culturing normal or cancer LGR5 stem cells in serum inhibits tissue-specific stemcell reproduction. The experimental rigor with which tissue-specific LGR5 stem cells have been studied and identified and the organoid cultures produced by these cells (Sato et al. 2009; Gao et al. 2014; Karthaus et al. 2014) has simply not been reproduced by the diversity of biomarkers claimed to identify these "so-called tissue-specific cancer stem cells" observed by many diverse research groups (Al-Hajj et al. 2003; Collins et al. 2005; Li et al. 2007; O'Brien et al. 2007; Ricci-Vitiani et al. 2007; Schatton et al. 2008).

Many years ago, several "cancer-specific" biomarkers were identified in liver cancers $(\alpha$ fetoprotein) and colon cancers (carcinoembryonic antigen). On further study, it became clear that these proteins were expressed in the normal 
fetus in a tissue-specific fashion and were reexpressed in replicating cancerous tissue. As our abilities to study gene expression patterns in the fetus and in the adult have developed, a large number of so-called fetal proteins have been uncovered and are also expressed during wound healing and in cancerous cells. In many cases, it is these fetal-tissue-specific proteins that are reexpressed in cancers that have often been confused with true markers for cancer-tissuespecific stem cells. Thus, a comparison of the gene expression patterns in normal adult tissues with cancerous tissues is not a good criterion for the so-called cancer-stem-cell biomarkers. Biomarkers for tissue-specific stem cells, cancerous and normal, should reflect a functional property of the stem cell, its division, and epigenetic state. The R-spondin-LGR-5 pathway is a good example of this and seems to be the best candidate.

\section{Teratocarcinoma Stem Cells}

Before the clearly defined (LGR-5) tissue-specific normal and cancer stem cells were identified, tumors of the germline, termed teratomas (benign) and teratocarcinomas (malignant), were being described in humans and mice. The mouse model has been studied in some detail. There are inbred stains of mice that develop testicular teratocarcinomas and teratomas (129Sv strain in males only and LT strain in females only) at low but reproducible frequencies (Stevens and Varnum 1974; Lutzker and Levine 1996; Muller et al. 2000). Similar patterns of human families with ovarian teratomas are not uncommon. This means that there are sex-limited inherited genetic predispositions for these tumors. One might speculate that these predispositions reside in gene(s) that regulate the epigenetic state of germ cell development. The tumors formed are composed of two cell types: (1) malignant pluripotent stem cells termed embryonal carcinoma cells, and (2) differentiated benign cells. A single malignant embryonal carcinoma cell can form a tumor containing differentiated cells or not (Kleinsmith and Pierce 1964). An embryonal carcinoma cell is also capable of differentiating into many or a few (depends on the tumor) benign cell and tissue types, which fail to form tumors when injected into isogenic mice. Thus differentiation rolls in an epigenetic program that overrides the malignant stem-cell program harbored in an embryonial carcinoma cell. Here again, a single cancer stem cell, the embryonal carcinoma cell, can reproduce symmetrically to produce other tumorigenic stem cells. From this pool of stem cells, one or a few cells often stop or slow cell division, which triggers lineage-specific differentiation, often in many different tissue-specific directions so that tumors may contain bone, hair, nails, teeth, or other structures in the ovary or testis. In some cases, tumors differentiate out of existence, containing no embryonal carcinoma cells and result in a spontaneous remission. This tumor type provides a rather clear example of a cancer stem cell with its tumorigenic phenotype regulated epigenetically.

What is the reason to elucidate each of these classes of stem cells in a collection whose theme is dedicated to p53 functions in cancers? Over the past 5 to 10 years, it has become clearer that the $\mathrm{p} 53$ protein plays a critical role in regulating normal and cancerous stem cells and in ensuring the stability of the epigenetic state. The evidence for this comes from examples in invertebrates, vertebrates, and most clearly from mammals. The remainder of this work will review this evidence so as to elucidate the role of the $\mathrm{p} 53$ protein in stem-cell regulation and epigenetic fidelity.

\section{THE ROLE OF THE p53 FAMILY OF GENES IN GERMLINE TOTIPOTENT STEM CELLS}

Various ancestral members of the p53, p63, and p73 family of transcription factors (Belyi et al. 2010) have been found and studied in the invertebrates, the choanoflagellates (p53), Nematostella sea anemones (p63/p73), Caenorhabditis elegans round worm (p63/p73), Drosophila (p63/p73), and planaria flatworm (p63-like), each of which contain a single p53 family ancestor. In the vertebrates, the three paralogs, p53, p63, and p73, evolved distinct aminoacid sequences, genome organizations, and distinct subsets of genes that are regulated by these 
A.J. Levine et al.

transcription factors (although there remains some overlap) (Ortt and Sinha 2006; Vigano et al. 2006; Smeenk et al. 2008; Tozluoglu et al. 2008; Belyi et al. 2010). Each of these three transcription factors has also evolved distinct functions and even different tissue specificities (see Fig. 2). It is in the vertebrates that $\mathrm{p} 53$ is split out to become a major somatic cell tumor suppressor. In invertebrates, such as Drosophila, C. elegans, and the Nematostella, the p63/73 ancestor protein functions in the germline, the totipotent stem cell, to protect against DNA damage of the egg and the sperm. After DNA damage, the p63/73 ancestor induces the transcription of a set of genes that leads to an apoptotic pathway similar to that found in mammals (Pankow and Bamberger 2007). In C. elegans, nutrient starvation results in the p63/p73 ancestor gene product killing germline cells and preventing the laying of fertilized eggs into a barren environment (Conradt and Horvitz 1998; Derry et al. 2001; Schumacher et al. 2005). In the mouse, a similar function has been taken over by p63 in the ovary, protecting germline integrity in eggs (this is a sexually dimorphic, female-specific function) (Suh et al. 2006). In all of these cases (in invertebrates and some female vertebrates), the fidelity of the germline genome is enforced by p63-like gene functions. In the mouse and the human, p63 also functions as a tissue-specific stem-cell transcription factor for the self-renewal of skin.

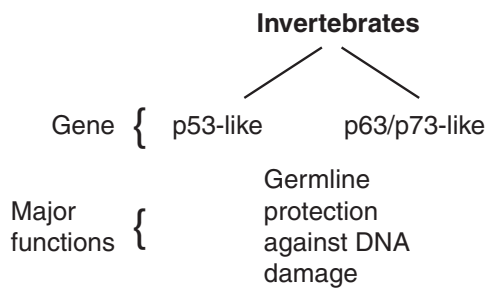

Does p53 play a role in the germline integrity of the genome in mammals? This idea was first tested in mice that had no p53 genes, the p53 knockout mice. In some strains of mice (C57Bl6), a variable percentage $(33 \%)$ of female mice have birth defects, which include exencephalic mice and runted mice (Donehower et al. 1992; Armstrong et al. 1995; Sah et al. 1995). This sexually dimorphic defect suggested a defect in the epigenetic programming for the expression of genes only in female offspring or possible genomic instability expressed during female mouse development (estrogen driven). This idea was tested in the offspring of p53-null female mice. The DNA methylation pattern associated with the regulation of the insulin-like growth-factor-2 gene in the livers of some of these female mice differed (hypermethylation) from wild-type female mice (Yi et al. 2012). This result suggested that the absence of the p53 gene in mothers impacted the imprinting of the offspring of these mice. In a probabilistic manner (not $100 \%$ of the time), in the absence of p53 functioning in a cell, the programmed epigenetic stability of a cell is reduced.

Next, these p53 knockout mice were bred over 12 generations and copy-number variations (CNVs) in the genome of the offspring were assayed by DNA array hybridization (Ariffin et al. 2014). CNVs have been observed in about one in 50 live births in p53 wild-type

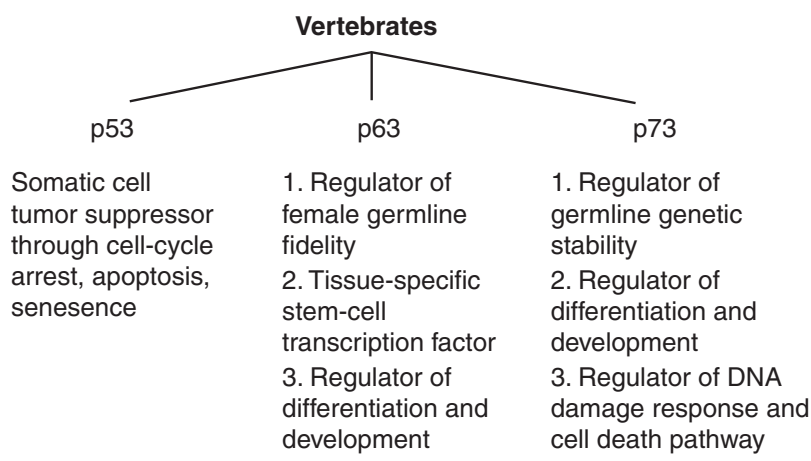

Figure 2. Different functions of the p53 family of genes-p53, p63, p73. Ancestral members of the p53, p63, and p73 family of transcription factors have been found and studied in the invertebrates, in which their primary roles are to protect the germline from DNA damage. In the vertebrates, the three paralogs ( $\mathrm{p} 53$, p63, and p73) have distinct transcription factor functions and different tissue specificities. 
mice, and, in p53 knockout mice, the frequency of CNVs was the same (Watkins-Chow and Pavan 2008). In humans, individuals with one mutant p53 allele are known to develop cancers at a high frequency, termed the Li-Fraumeni syndrome. In families that can be followed over three generations with the Li-Fraumeni syndrome, it is common to observe that first cancers arise at younger ages in the second and third generations. This has been called anticipation (Trkova et al. 2002). With some inherited neurological diseases, an earlier onset of symptoms (anticipation) in the younger generation is accompanied by an increase in a $\mathrm{G} / \mathrm{C}$-rich trinucleotide repeat $5^{\prime}$ to the gene or in the protein. This is not the case for the p53 mutant gene in Li-Fraumeni syndrome (Ariffin et al. 2014). A tempting hypothesis is that the $\mathrm{p} 53$ protein plays a role in the germline similar to its function in the somatic tissues, it protects against genomic instability, killing cells that undergo such changes in the genome. CNVs are very common in p53 mutant cancers (the somatic tissues). DNA sequencing of blood samples from family members carrying p53 mutations or family members with wild-type p53 genes over two generations in a Li-Fraumeni family with anticipation (a lowering of the age of onset of the first tumor) failed to show any increase in CNVs over subsequent generations when comparing individuals with two copies of wild-type p53 with those with one copy (Ariffin et al. 2014). Both the results from mice and the results from humans have failed to show that $\mathrm{p} 53$ has a role in protecting genome stability in the germline in mammals as it and/or its family members do in invertebrates (Ariffin et al. 2014). p63, however, does enforce germline genome stability in females (Suh et al. 2006).

\section{THE ROLE OF p53 IN SELF-RENEWAL AND TISSUE REGENERATION}

Planarians have been shown to have a single p53-like gene, named Smed-p53 (with no MDM-2 or p21-like genes found) (Pearson and Sanchez Alvarado 2010). The DNA-binding domain binds in a sequence-specific man- ner to the p53/63 DNA consensus sequence, and hotspot mutations in this gene eliminate DNA binding. There is no SAM domain (like p63) and only one apparent transcript has been identified to date (Pearson and Sanchez Alvarado 2010). As studied in the laboratory, these flatworms do not have a sexual cycle; they divide by binary fission and subsequent regeneration of missing body parts. There is a great deal of tissue turnover and both regeneration and turnover are mediated by adult somatic stem cells called neoblasts. In situ hybridization with a Smed-p53 probe to whole mounts of the flatworm found that the p53 transcript was predominately expressed in the newly made progeny cells produced by the stem cells of the worm. Planarians can be fed bacteria that contain a p53 siRNA (double-stranded RNA), which acts to eliminate the Smed-p53 gene expression. When this is done, self-renewal of normal tissue turnover is disrupted and the worms eventually die. When the siRNA is used to block p53 in amputated worms, tissue regeneration is inhibited. The regeneration of both the head and tail of the worm is inhibited by eliminating the p53 protein indicating that $\mathrm{p} 53$ plays a role in early and/or many different pathways of tissue differentiation (Pearson and Sanchez Alvarado 2010). An analysis of stem-cell function after siRNA addition showed that the removal of p53 resulted in a continued active stem-cell proliferation, followed in time with stem-cell depletion. The absence of p53 enhances stem-cell proliferation. The presence of p53 in the progeny cells derived from stem cells suggests that p53 promotes differentiation when it acts in the stem cell with the subsequent loss of stem cells. The absence of Smed-p53 in stem cells after a set of active divisions (i.e., a long-term loss of p53 in the stem cell) also resulted in the loss of stem cells, suggesting a possible role for p53 in longterm maintenance of stem-cell division in the planarian (Pearson and Sanchez Alvarado 2010).

Some vertebrates, such as amphibians and fish, have retained the ability to regenerate tissues after amputation. In these animals, regeneration appears to be accomplished by the epigenetic reprogramming of the differentiated 
A.J. Levine et al.

cells forming a group of stem cells termed blastema. After a period of proliferation, these blastema cells undergo differentiation to replace the lost tissue types. In the amputation of a salamander limb, the dedifferentiation of muscle, cartilage, and connective tissue form the blastema containing tissue-specific stem cells in a process that is similar to the mammalian iPS cells discussed above. Interestingly, p53 levels decline and are almost undetectable in the formation of the blastema by active replication. On an increase in p53 levels, the cells differentiate, regenerating the limb (Yun et al. 2013). A p53 transcriptional reporter showed p53 activity declines during the formation and proliferation of the blastema followed by a strong increase of p53 activity in mesenchymal cells undergoing differentiation. The use of nutlin 3a, which increases p53 levels and activity, blocked the formation of the blastema and regeneration (Yun et al. 2013). In an in vitro assay for myotube formation from blastema cells, nutlin increased myotube formation indicating that $\mathrm{p} 53$ promoted the differentiation of the blastema cells. Consistent with this is that $\alpha$-pifithrin, an inhibitor of p53 activity, blocked the formation of myotubes from a preformed blastema. These studies with vertebrates are consistent with the observations with planarians (Pearson and Sanchez Alvarado 2010; Yun et al. 2013). Lower p53 levels promote stem-cell formation and proliferation, whereas higher p53 levels and activity promote differentiation of stem cells.

\section{p53 AND MAMMALIAN STEM CELLS}

Studies with the formation and proliferation of iPS cells in mice and humans are totally consistent with this hypothesis. The addition of cMYC, KLF-4, OCT-2, and SOX-4 transcription factors to fibroblastic cells in culture resulted in a small percentage of cells ( $1 \%$ to $0.1 \%$ ) undergoing reprogramming to form iPS cells in culture (over a period of months) (Takahashi et al. 2007; Puzio-Kuter and Levine 2009). These iPS cells had the ability to contribute many cell types and tissue types during subsequent differentiation when placed in a mouse blastocyst re- sulting in the formation of mice in vivo (much like inner mass cells). High levels of both c-MYC and KLF-4 can function as oncogenes so complete mouse development was compromised by tumor formation. Remarkably, the absence of p53 in the fibroblasts being reprogrammed by these transcription factors permits the reprogramming of fibroblasts to iPS cells to occur with only SOX-2 and OCT- 4 , in a much higher percentage of the cells (10\% to $80 \%)$ and in a much shorter time (a week) (Hong et al. 2009; Kawamura et al. 2009; Li et al. 2009; Marion et al. 2009; Puzio-Kuter and Levine 2009). The absence of p53, replacing c-MYC and KLF-4, could indicate that p53 retards the growth of both the differentiated cell (the fibroblast) that needs to be reprogrammed and the stem cell (iPS cell) once it is produced. It is likely that a rapid set of cell divisions are required in the fibroblast for epigenetic reprogramming and that c-MYC and KLF-4 can help that process or the absence of p53 can help that process. It has been shown that the loss of $\mathrm{p} 53$ results in the immortalization of mouse fibroblasts in culture and this is just a different assay for self-renewal of cells in culture (Harvey and Levine 1991). When a temperature-sensitive p53 mutation was used to follow the reprogramming of fibroblasts to iPS cells, it was shown that mutant p53 $\left(\right.$ at $39^{\circ} \mathrm{C}$ ) permitted fibroblasts to be efficiently reprogrammed to iPS cells. When the mutant p53 cells were shifted to wild-type p53 (at $\left.32^{\circ} \mathrm{C}\right)$ at any time in the reprogramming to iPS cells, including after iPS cells were produced, the iPS cells were lost and differentiated cells appeared (Yi et al. 2012). These temperature shift experiments were most consistent with the idea that p53 impacts proliferation of the fibroblastic cells being reprogrammed and that contributes to the poor efficiency of iPS cell formation. An active 553 protein negatively impacts the proliferation of the iPS cells reducing their numbers. If p53 levels and activity get too high in the iPS cells, then differentiation is promoted and stem cells are lost. The use of fibroblasts derived from knockout mice without a p21 gene and the temperature-sensitive p53 mutation showed that the p53-regulated p21 gene (which in turn regulates progression through the cell cycle) plays a 
role in the efficiency of formation of iPS cells, but not as large a role as p53 loss by itself (Yi et al. 2012). The absence of p53 functions produces many more iPS cells derived from fibroblasts than are observed in the absence of p21 in a p53 wild-type genetic background (Yi et al. 2012). Therefore, some other p53-regulated functions, in addition to p21 and the blocking of cell division, impacts the formation of these iPS cells after addition of the Yamanaka factors. What are the other p53-regulated functions that might impact the efficiency of iPS cell formation? Using a temperature-sensitive p53 mutation in a fibroblast cell and shifting the temperature (turning on and off p53 function) during the formation of iPS cells in culture, the absence of p53 appears to aid in both rapid cell division (a p21 function), which occurs early in time and at a later stage during epigenetic reprogramming (Yi et al. 2012). It is as if the absence of p53 permits the epigenetic changes to occur at a higher probability in the formation of a stem cell. That is the same conclusion from experiments described above using female p53 knockout mice who gave birth to female defective offspring, which had altered imprinting of the insulin-like growth factor 2 (IGF-2) gene (Yi et al. 2012).

Because normal developmental changes take place in cells with a wild-type p53 gene and protein, how do these stem cells propagate and reprogram? One answer is that some types of protein modifications inactivate p53 functions. Indeed, during reprogramming of iPS cells from fibroblasts the Aurora A kinase phosphorylates the p53 protein at amino-acid residues Ser212 and Ser312, which results in the inactivation of the p53 protein (Lee et al. 2012). The Aurora kinases are important in mitotic and meiotic segregation of chromosomes. Some cancer cells have gene amplifications of Aurora kinases and many cancers overexpress these kinases, which can then inactivate p53 wild-type activity. The expression of Aurora kinases in meiosis suggests a way to inactivate p53 in totipotent stem cells (meiosis) as well as in iPS cells being reprogrammed in culture.

A second example of the inactivation of the p53 protein in stem cells has been described with human embryonic stem (ES) cells, which are derived from inner mass stem cells (Jain et al. 2012). In human ES cells, p53 is in the nucleus but it is inactive for transcription because the lysine residues at 120 and 373 are not acetylated. The addition of retinoic acid to these stem cells begins a program of cellular differentiation resulting in the $\mathrm{CBP} / \mathrm{p} 300$ histone acetylase, acetylating the p53 residues 120 and 373 . This results in the dissociation of HDM2 and TRIM24 (the negative regulators of p53) from the p53 protein and an increased stability and transcriptional activity of $\mathrm{p} 53$. The activated p53 protein transcribes two small nuclear RNAs, mir349 and mir145, both of which negatively regulate a set of transcription factors, Oct-4, KLF-4, Lin28A, and Sox-2, which normally favor stem-cell maintenance. The inhibition of these transcription factors then promotes differentiation and stops or reduces pluripotency (Jain et al. 2012).

\section{p53 IN CANCEROUS STEM CELLS}

The behavior of the $\mathrm{p} 53$ protein in teratocarcinoma stem cells, the embryonal carcinoma cells, follows a similar course, with some twists. Embryonal carcinoma cells express very high levels of p53 and, when these cells differentiate, p53 levels decline (Lutzker and Levine 1996). On the face of it, this would seem to be quite different from every example of a stem cell examined above. Interestingly, the high levels of p53 in the embryonal carcinoma cells are the result of a failure of p53 function in embryonial carcinoma stem cells. The inactive p53 transcription factor in these stem cells fails to produce p21 (leading to active replication) and MDM-2 (leading to high levels of inactive p53 protein) (Lutzker and Levine 1996). On induction of differentiation, p53 becomes active, MDM-2 is made and p53 levels decrease, and cell division slows as p21 is made (Lutzker and Levine 1996). Although it is not known what inactivates p53 activity in the embryonal carcinoma stem cells, the Aurora A kinase or even the presence of an histone deacetylase (HDAC) that removes acetyl groups from p53 amino-acid residues 120 or 373 are good candidates. 
A.J. Levine et al.

DNA damage also activates a functional transcriptionally active 553 protein in embryonal carcinoma cells. Consistent with these observations is that the great majority (98\%) of human and mouse teratocarcinomas have a wild-type p53 gene and protein. This would be expected if there were no selection pressure by the cancerous cells to inactivate $\mathrm{p} 53$ by mutation because it is inactive in those cells as a result of its protein modifications. Testicular teratocarcinomas are unusual in that they are quite curable on treatment with cis-platinum drugs, DNA-damaging agents, which activate p53 in the embryonal carcinoma cells. Thus, the inactive form of $\mathrm{p} 53$ in a stem cell, sparing it from the selection of mutations in the p53 gene, permits a vigorous response to DNA damage by a p53-mediated differentiation and/or apoptosis. Stem cells in the bone marrow, the gut, and in hair follicles are similarly very sensitive to DNA-damaging drugs used in chemotherapy and the activation of $\mathrm{p} 53$ by DNA damage. Indeed, these are the major side effects of chemotherapy.

\section{A ROLE FOR p53 IN THE MAINTENANCE OF STEM CELLS}

We might well conclude from all of these clearly consistent studies that p53 is largely inactive in stem cells, which permits these cells to replicate and maintain epigenetic plasticity. The results with planarians, however, suggested that p53 was essential for maintaining the stem-cell state over longer time scales (Belyi et al. 2010; Pearson and Sanchez Alvarado 2010). Similarly, the experiments using female p53 knockout mice to show that the fidelity of female-specific DNA imprinting of female offspring could be altered by the loss of p53 suggests a role in regulating the stability of the epigenetic state in stem-cell maintenance or development (Yi et al. 2012). A set of functions for p53 in regulating the stem-cell state in human ES cells has recently come from the work of Barton and her colleagues (Jain et al. 2012). In Jain et al. (2012), p53 is very low in ES cells. Its activation induces miR34a and miR145, which down-regulate SOX2, OCT4, LKF4, LIN28, and SIRT1, pro- moting differentiation. In Bao et al. (2015), the reprogramming of somatic cells into iPS cells is inhibited by a p53-regulated lincRNAp21, which associates with SETB1 and DNMT1 to maintain the differentiated epigenetic patterns of promoters such as SOX2 and NANOG. Thus, in the case of activating p53 function in stem cells, p53 promotes an epigenetic program of differentiation and, in the epigenetic reprogramming of a cell (dedifferentiation), a functional p53 prevents an epigenetic change and ensures stability of the epigenetic state.

These conclusions bring up a set of questions about how the activity of p53 is regulated in stem cells and in differentiating cells leading to two different states controlled by a p53mediated bivalent switch. Virtually every experiment reviewed here concluded that the p53 protein activity is off in stem cells and turning it on causes differentiation. If so, how are p53 functions required for the long-term stability of stem cells and their epigenetic program? There is an interesting possible solution to this problem. The $\mathrm{p} 53$ protein has two distinct transcriptional activation domains, which reside at amino-acid residues $22 / 23$ and 53/54 in the protein. These two domains regulate the transcription of distinct sets of genes that share the same DNA-binding sequence (see Raj and Attardi 2016, and references therein). The p53regulated proteins that have been examined in a variety of stem cells, p21, MDM2, etc., are all produced from the first transcriptional activation domain at residues $22 / 23$. That has been shown by mutating residues $22 / 23$ in the p53 gene, and the protein now fails to promote the transcription of p21 and MDM2 (Lin et al. 1994a,b). These observations suggest that the $22 / 23$ transcriptional activation domain is then silent for transcription in stem cells, and one would predict that it would transactivate the siRNAs that promote differentiation. If, on the other hand, the p53 transcriptional activation domain at $53 / 54$ transactivates functions that maintain the stem-cell pluripotent state then the p53 protein in stem cells would be active from only one of its domains. This hypothesis has the advantage of explaining all of the results from the experiments reviewed here. 
It also has the advantage of being testable by mutations in each of the transactivating domains. In line with this hypothesis is evidence that the main form of p53 present in mouse ES cells is $\Delta 40 \mathrm{p} 53$, a protein isoform that lacks the first 39 residues of $\mathrm{p} 53$, thus removing the first transcriptional activation domain (Ungewitter and Scrable 2010). This p53 isoform, which is produced by internal initiation of translation at codon 40, either from fully spliced p53 messenger RNA (mRNA) or from an alternatively spliced form (Courtois et al. 2004; Ghosh et al. 2004), remains the major isoform of p53 during early embryogenesis in the mouse. Haploinsufficiency for $\Delta 40 \mathrm{p} 53$ causes a loss of pluripotency in ES cells and acquisition of a somatic or differentiated cell cycle, whereas increased dosage of $\Delta 40 \mathrm{p} 53$ prolongs pluripotency and inhibits progression to a more differentiated state (Ungewitter and Scrable 2010). These observations explain how p53 can function to promote a pluripotent state at one time and initiate differentiation in another time and state. Interestingly, the $\Delta 40 \mathrm{p} 53$ isoform is a structural and functional counterpart of the $\Delta \mathrm{N}$ isoforms of p63 and p73, suggesting that expression as alternative amino-terminal isoforms is a shared characteristic of all members of the family (Courtois et al. 2004; Bourdon et al. 2005). If correct, the p53 alternative transcriptional activation domains in stem cells are regulated by a bispecific epigenetic switch. The question then becomes how are isoform expression patterns and/or the transcriptional activation domains of transcription factors regulated so that this leads to selective mRNA gene expression? The likely answer is through RNA and protein modifications that reflect the epigenetic state of the cell type.

\section{GERMLINE p53 MUTATIONS IN HUMANS AND MICE SUGGEST A ROLE FOR p53 FUNCTION IN STEM CELLS}

A small number of humans and families harbor p53 mutations, which have been shown in 70\% of the cases to be the cause of the Li-Fraumeni syndrome (Olivier et al. 2010). The Li-Fraumeni syndrome is a rare autosomal-dominant disorder, which commonly results in high risk for a subset of cancers including sarcomas, brain tumors, adrenal cortical carcinoma, and osteosarcoma in children and teenagers and hematopoietic malignancies and premenopausal breast cancer in young adults. p53 mutation carriers also have a moderately increased risk of colorectal cancer and lung cancer in adults. Patients can develop multiple independent primary cancers (up to seven and even more in the case of multiple leiomyosarcoma) and have an estimated risk of $\sim 95 \%$ for developing a cancer by the age of 70 years $(54 \%$ at age 30$)$. In humans and their families, a single p53 mutant allele is inherited and the wild-type allele is then lost by gene conversion in most, but not all, tumors. The International Association of Cancer Research (IARC, Lyon, France) has collected a great deal of information about this syndrome and the patients that develop cancers (IARC TP53 database; p53.iarc.fr). One of the first and most striking conclusions to derive from the analysis of cancer patterns in germline p53 mutations carriers is that persons that inherit p53 mutations preferentially develop over their lifetime cancers that derive from mesenchymal and ectodermal tissues with 10- to 1000-fold greater frequency than observed in the general population, but have only low-risk (only twoto fivefold higher than observed in the wildtype population) for developing cancer from endodermal tissues (Fig. 3). This is in contrast with somatic p53 mutations that largely contribute to cancers, such as colon, lung, pancreatic, and ovarian (all of endodermal origin), where the frequency of p53 somatic mutations varies between $50 \%$ and $100 \%$ of the tumors. Clearly, the impact of a germline or a somatic p53 mutation is modified dramatically by the developmental origin of the tissue. An identical p53 mutational allele that is inherited or acquired somatically may function differently depending on the tissue in which it resides. One possible explanation of this distinction is that early in development the embryo is partitioned into lineage-specific stem cells that produce endoderm, mesoderm, and ectoderm, and each of these lineages produce tissue-specific stem cells. Germline p53 mutations act early in tumor de- 
A.J. Levine et al.

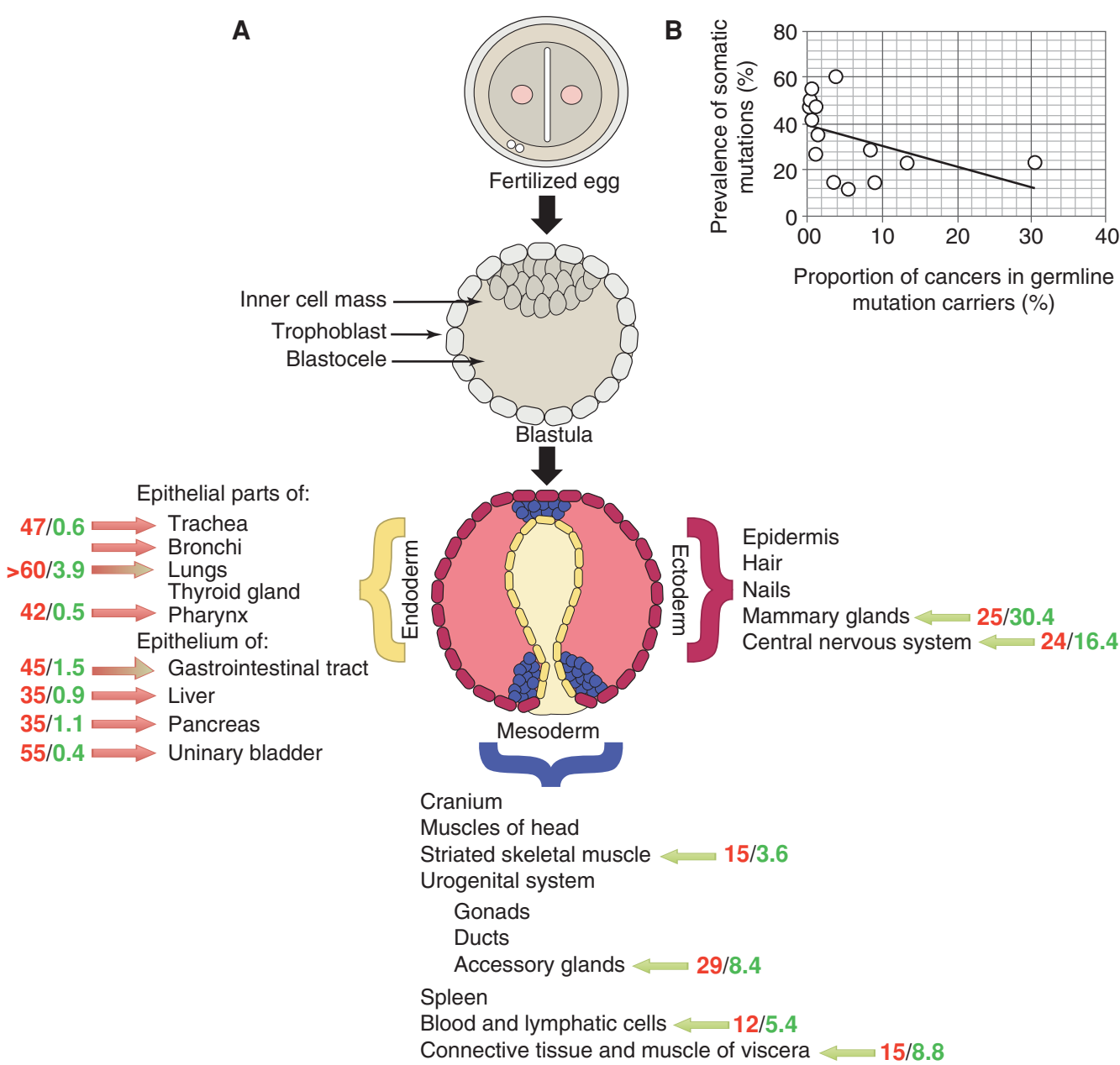

Figure 3. Distinct embryonic origin for tumors with high rates of somatic TP53 mutations and tumors frequently associated with germline TP53 mutations. (A) Tissues/organs in which tumors with high rates of TP53 mutations $(>35 \%)$ occur are indicated by a red arrow (\% somatic mutations, numbers in red). Tissues/organs in which tumors frequently develop in subjects who carry a germline TP53 mutation are indicated by a green arrow ( $\%$ of all cancer diagnoses in mutation carriers, numbers in green). Tumors that are frequent in mutation carriers are different from those that often contain TP53 somatic mutations, with the exception of cancers of the lung and colorectum (dual color red/green arrows), which are somatically mutated on TP53 in $>35 \%$ of the case, and yet represent each $>1.5 \%$ of the cancers diagnosed in germline mutation carriers. $(B)$ Inverse relationship between prevalence of somatic mutation in cancers and proportion of the corresponding diagnosis in mutation carriers.

velopment, whereas somatic mutations can act and be selected for at later times in tumor development and so the timing of a selection for a p53 mutation in the evolution of a cancer may differ, depending on which type of stem cell a p53 mutation (somatic or germline) functions in or fails to act in. The second observation emerging from the data set of patients with inherited mutations is that the tissue specificity and type of tumor developed by a $\mathrm{Li}-$ Fraumeni patient differs depending on the chronological age of the patient (see Fig. 4). In particular, LiFraumeni patients have a much-increased frequency $(100-1000 \times)$ of several childhood can- 
p53 in Stem-Cell Biology and Epigenetic Regulation

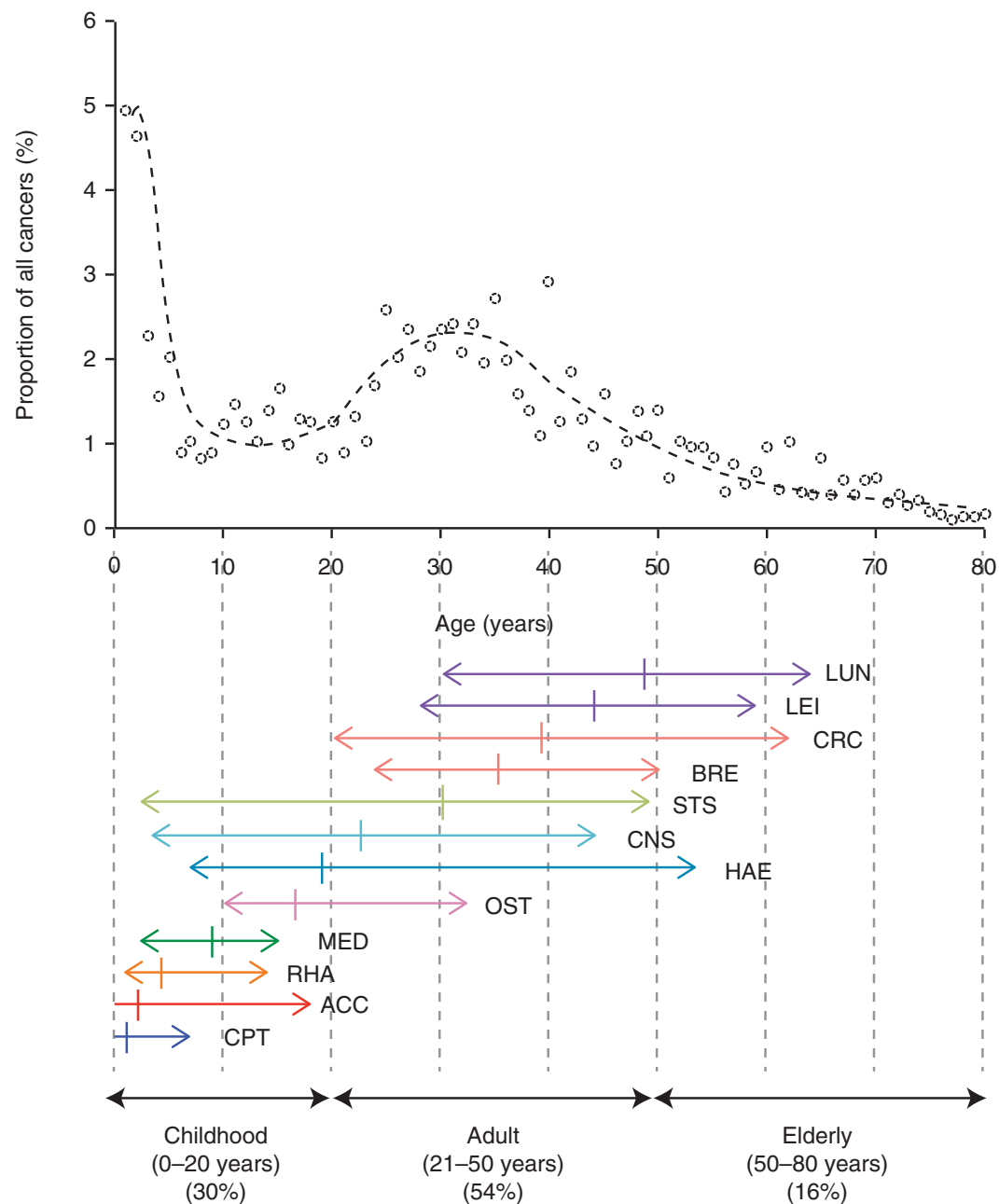

Figure 4. Inherited cancer patterns in germline TP53 mutation carriers. (Top) Proportion of all cancers occurring by each year of age in TP53 mutation carriers. (Middle) Temporal distribution of frequent cancers in TP53 mutation carriers. Arrows indicate the age span during which $75 \%$ of the cancers occur. Vertical bars in each arrow: median age at diagnosis. CPT, choroid plexus carcinoma; ACC, adrenal cortical carcinoma; RHA, rhabdomyosarcoma; MED, medulloblastoma; OST, osteosarcoma; HAE, hematopoietic malignancies; CNS, brain tumors (excluding CPTand MED); STS, soft tissue sarcoma (excluding RHA and LEI); BRE, breast cancer; CRC, colorectal cancer; LEI, leiomyosarcoma; LUN, lung cancer. (Bottom) Double-ended arrows indicate the phases of low-frequency stimulation (LFS) characterized by different magnitudes of excess risk of cancer as compared with noncarrier populations, including childhood phase (excess cancer risk: 20- to 1000-fold), adult phase (excess cancer risk: five- to 20-fold), and elderly phase (excess cancer risk: one- to fivefold). (Data from IARC TP53 database, germline mutation dataset, version R17; p53.iarc.fr/DownloadDataset.aspx.)

cers, which are otherwise extremely rare in the general population. These cancers include adrenal cortical carcinoma (ACC), choroid plexus carcinoma (CPT), medulloblastoma (MED), and rhabdomyosarcoma (RHA), 90\% of which occur before the age of 15 years in germline p53 mutation carriers. The association between these early cancers and germline p53 mutation is so strong that diagnosis of one of these cancers in a child is now considered as a criterion for referring the patient for p53 mutation testing even in the absence of familial history of 
A.J. Levine et al.

cancer (Tinat et al. 2009). Other cancers occurring later in the life of $\mathrm{Li}-$ Fraumeni subjects also show strong temporal patterns. Osteosarcoma occurs at a median age of 16 years, glioblastoma and astrocytoma occur essentially in teenagers and young adults (median age: 24 years), whereas specific forms of soft tissue sarcoma such as leiomyosarcoma tend to occur at later ages (median age: 44 years). On the other hand, breast cancer occurs almost exclusively before menopause (median age: 34 years), with a lifetime risk of $5 \times-10 \times$ compared with the general population. The majority of these breast cancers express HER2. Li-Fraumeni patients also have a modest increase of the risk to develop colorectal cancer $(2 \times-$ $3 \times)$, occurring at median age of 38 years, and lung cancer (mostly adenocarcinoma, occurring at median age of 48). Overall, these observations indicate that increased risk of cancer in p53 mutation carriers is not caused by improper guardianship of the genome in the face of oncogenic DNA damage accumulating over a lifetime. Rather, the tissue- and time-specific cancer pattern suggests that germline p53 mutation interferes with essential functions controlling the fate of stem cells at critical points of growth and development during childhood and during aging. Indeed, the age at which a tumor arises and the tissue from which it derives may reflect the most active division of the tissue-specific stem cell and the active replication of the tissue that develops a cancer in Li-Fraumeni patients (Fig. 4). These observations point to unique, nonoverlapping p53 function at specific stages in development and aging. Perhaps the most remarkable observation is that, on reaching the age 55-60 years, subjects who carry a germline p53 mutation but have not yet developed cancer have a risk of cancer that is similar to the general population of equivalent age with wild-type $\mathrm{p} 53$ alleles. By 70 to 100 years of age, they have a risk of developing a cancer that is lower than the general population with wild-type p53 genes. This observation may be explained by the progressive, age-dependent exhaustion or depletion of pools of "at-risk" stem cells. It could also be explained by environmental variations, good fortune, or a genetic basis.
The genetic hypothesis suggests that there may be alleles of genes in the human genome, which function as suppressors for the loss of p53 activity or haplotypes, in which the loss of p53 activity from one mutant allele has no functional consequence on tumor suppression. Perhaps, the wild-type $\mathrm{p} 53$ protein from one allele is overexpressed or has a higher activity in this population of "cancer-resistant" individuals. Alternatively, there may be some rare alleles in other genes that back up p53 function.

As discussed above, the loss of the p53 protein does not appear to increase genomic instability in the germline of $\mathrm{Li}$-Fraumeni patients nor in mice that are bred from p53- null parents (Ariffin et al. 2014). This suggests that anticipation observed in Li-Fraumeni families (a lower age of onset of tumor development in successive generations of a family) is not a result of genomic instability in the germline. In fact, it occurs because the tumor type changes from older to younger ages of cancer onset. Probably, the best explanation of anticipation is that the first generation to acquire a spontaneous p53 mutation may survive to older ages and bear children because that p53 mutation is in a genetic background that suppresses p53 mutations. The children marry and dilute the protective genetic background over the second and third generations (the genetic background regresses to the mean). Indeed, only those families in which the first generation lives a long life can report anticipation so that there is an ascertainment bias in selecting grandparents with p53 mutations in the first of three generations. These ideas predict that there are genetic modifiers of a p53 mutation in one allele that helps to explain Li-Fraumeni patients that never develop cancers, and the same hypothesis explains genetic anticipation in families.

Mice with heterozygous p53 mutations in the germline also show a time- and type-restricted tumor pattern, similar to observations in humans (Fig. 5). Homozygous p53 knockout mice develop thymic lymphomas starting about 9 weeks after birth. In the thymus, each T-cell clone has a different $\mathrm{T}$-cell receptor resulting from a V-D-J recombinational joining of these genes and somatic mutations because of the 
p53 in Stem-Cell Biology and Epigenetic Regulation
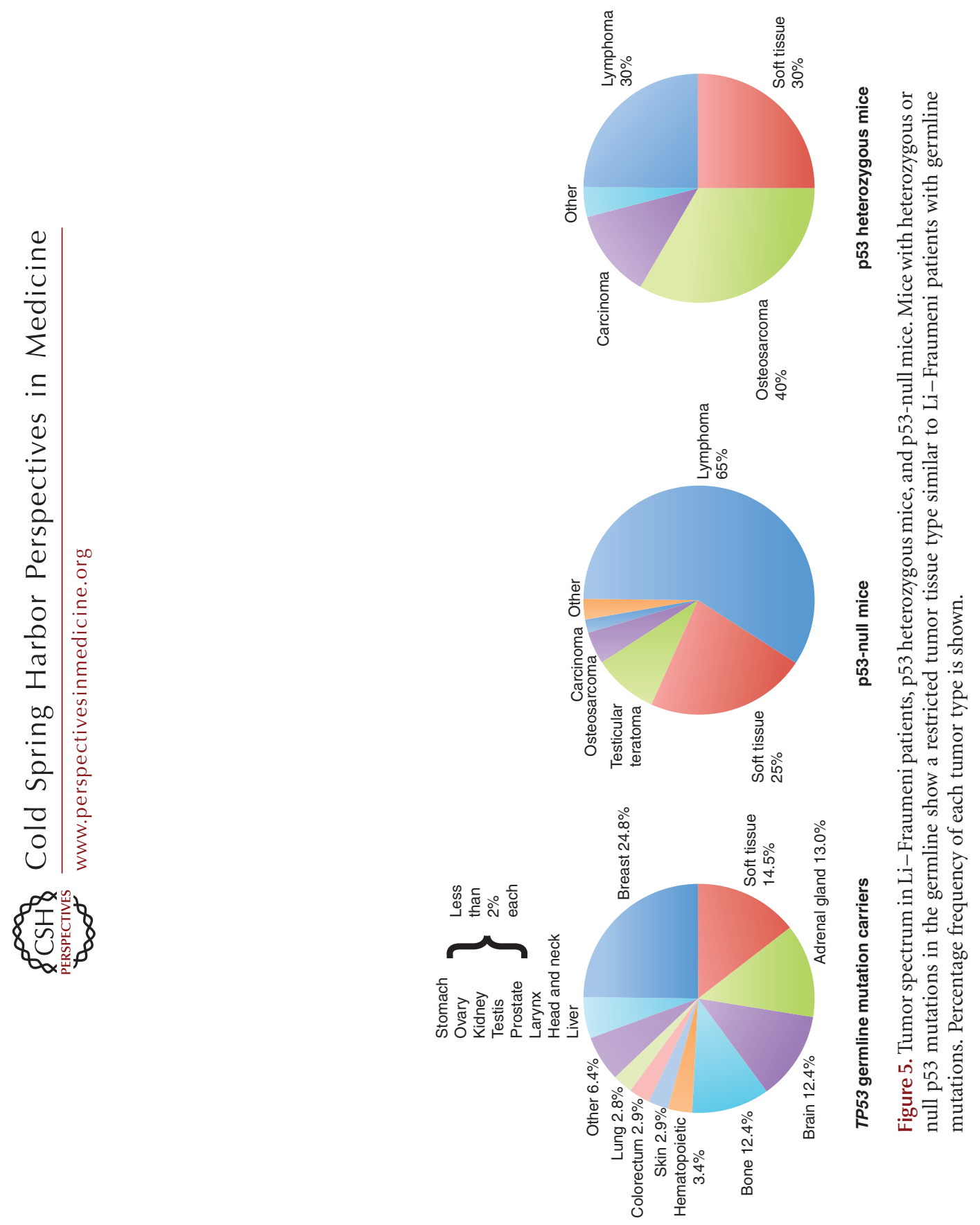
A.J. Levine et al.

terminal transferase addition of random nucleotides. The hypervariable region of the T-cell ( $\alpha$ or $\beta$ chain) receptor is about 200 nucleotides so that DNA primers can be placed on either side of that region and amplified by a polymerase chain reaction (PCR). The receptors can then be sequenced and the number of DNA reads is proportional to the copy numbers of each T-cell clone. In a thymus from a wildtype mouse, the largest T-cell clones represent between $0.01 \%$ and $0.1 \%$ of the total clones. In p53 knockout mice at 9 weeks of age, multiple clones of T cells at 2\%-20\% of total T cells are observed representing the T-cell lymphomas (Dudgeon et al. 2014). Thus, the tumors are oligoclonal with independent transformation events. The rate of transformation in a mouse varies from 0.3 to 0.8 clones per day. The frequency of point mutations in a tumor is $1 / \mathrm{Mb}$ of DNA (like a human breast or pancreatic cancer) (Lawrence et al. 2013), and the number of CNVs in the genome varies from 276 to 422, a very high rate of genomic rearrangements and aneuploidy, which is the phenotype associated with p53 mutations (i.e., genomic instability) (Dudgeon et al. 2014). By 20 weeks of age, about 60 transformed clones can be produced in each p53 knockout mouse, but these clones compete for resources and only two or three clones eventually represent up to $90 \%-95 \%$ of the tumor (Fig. 6). Independent tumors from indepen- dent mice have very similar gene mutations. All tumors start with homozygous loss of the p53 gene. In every case, the next mutation, which occurs before or in the T-cell stem cell, is the deletion of the phosphatase and tensin homolog (PTEN) gene. Every individual mouse carries many transformed T-cell clones, but the same PTEN deletion is found in that mouse, indicating that the mutation occurred and was selected for before the formation of the T-cell receptor (which is the method for determining the number of clones produced). Every different p53-null mouse carries a different PTEN deletion or mutation from other mice, but within a mouse all transformed clones have the same PTEN mutation. Next, gene amplifications of cyclin D (either D1, D2, or D3) and cdk-6 are observed after the T-cell receptor rearrangement and, finally, mutations in the Notch pathway are observed (Dudgeon et al. 2014). Thus, in T-cell lymphomas produced in mice that inherit a p53-null genotype, both the genes that are mutated and the order in which these mutations are selected are fixed and reproducible. The first mutation ( $\mathrm{p} 53^{-/-}$) functions as a gatekeeper found in the tissue-specific stem cell, which prescribes the selection of subsequent mutations that will lead to a tumor. Some of the mutations clearly occur in tissue-specific stem cells early in developmental life (p53 and PTEN). As in humans, the absence of p53 in

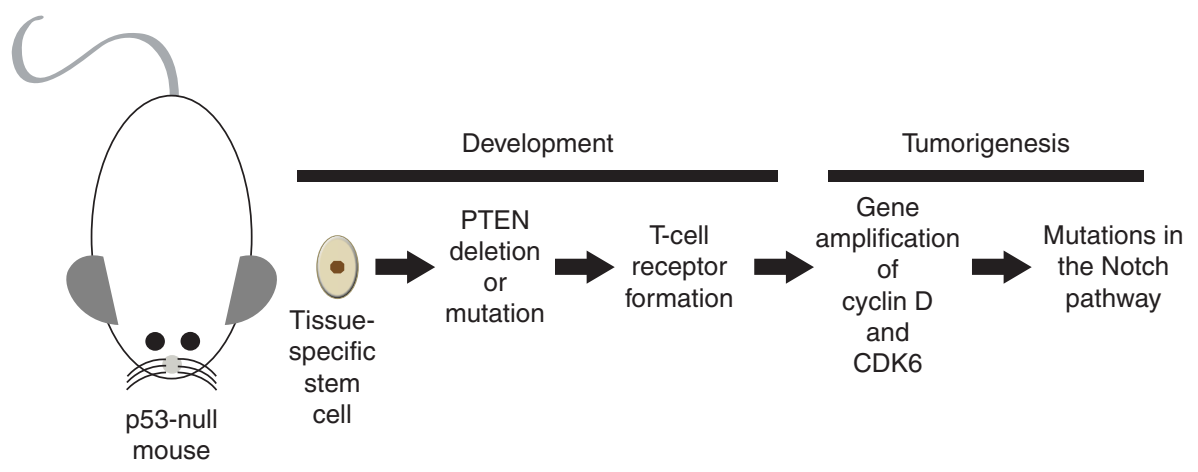

Figure 6. Development of mutations in thymic lymphomas of p53 knockout mice. Homozygous p53 knockout mice develop phosphatase and tensin homolog (PTEN) mutations in a tissue-specific stem cell before T-cell rearrangement. They then develop thymic lymphomas starting about 9 weeks after birth and go on to accumulate mutations in CDK4/6, cyclins, and the Notch pathway. 
development of these mice selects an actively replicating stem cell, the T-cell stem cell, to develop a tumor early in life (Dudgeon et al. 2014). Although the p53 protein has no role in enforcing germline genome stability, the major function of p53 in somatic cells and tissuespecific stem cells appears to be the guardian of the genome, so that tumors with p53 mutations most commonly have large levels of genome instability. We can see this in inherited cancers with BRCA-1 and -2 mutations (reduced efficiency of homologous DNA repair). In these individuals, the p53 protein kills the cells that make genome mistakes in repair, preventing a tumor. For a BRCA-1- or -2-induced tumor to form, p53 must be mutated or inactivated so that p53 acts as a suppressor of defective homologous DNA repair (Jonkers et al. 2001; Xu et al. 2001). The fact that ovarian cancers are caused by genome instability is reflected in the observation that virtually $100 \%$ of serous ovarian cancers have p53 mutations, as do triple negative breast cancers (Havrilesky et al. 2003; Dumay et al. 2013; Turner et al. 2013).

\section{THE ROLE OF THE p53 PROTEIN IN EPIGENETIC REGULATION OF THE GENOME}

Most of the evidence reviewed above is consistent with an inactive role for the $\mathrm{p} 53$ protein in tissue-specific stem cells and when it becomes functional it slows the rate of cell division and promotes differentiation (Yi et al. 2012). A few lines of evidence (see the discussion on the planarians and the role for a 553 -splice form maintaining stem-cell pluripotency) suggest that p53 has additional roles to play in long-term stemcell maintenance. There was also evidence that p53 enforced the stability of the epigenome (i.e., it slowed the efficiency and rate of producing iPS cells, and the absence of p53 altered the epigenetic imprinting of the IGF-2 locus in female mice) much like it enforces the stability of the somatic genome. A number of additional experiments are consistent with this idea. Experiments by Jackson-Grusby et al. (2001) showed that the floxed loss of the DNA-methyltransferase-1 gene from fibroblastic cells in culture resulted in the failure to copy the meth- ylcytosine pattern in DNA. After two generations of cell division, the cells in culture were killed by a p53-mediated apoptosis. An interpretation of this result is that the $\mathrm{p} 53$ protein senses the failure to copy the epigenetic marks on DNA (and the associated chromatin) and this results in the p53-regulated transcription of its apoptotic pathway. This result could be similar to the inhibitory role of p53 in reducing the reprogramming of iPS cells from fibroblasts in the experiments by Yamanaka and colleagues (Takahashi et al. 2007; Hong et al. 2009; Kawamura et al. 2009; Li et al. 2009; Marion et al. 2009). In human breast cancer cells (Mizuno et al. 2010) and prostate cancer cells (Markert et al. 2011), there is a strong correlation between the loss of p53 functions and the presence of an ES-cell messenger RNA profile or signature as observed by microarrays. In many cancers, the loss of p53 gene functions are associated with the expression of endogenous retrovirus RNAs and retrotransposon RNAs with concurrent epigenetic changes at those loci (JacksonGrusby et al. 2001; Haoudi et al. 2004; Harris et al. 2010; Noutsopoulos et al. 2010). These data suggest that the loss of p53 functions increase the probability to alter the epigenetic landscape of the genome.

The Serrano group (Nieto et al. 2004) was the first to report that the inhibitor of the DNAmethyltransferase-1 protein, 5-aza-2-deoxycytodine (decitibine), which incorporates into DNA at cytosine residues and prevents further DNA methylation, led to the apoptosis of cells treated with this drug when the cells contained a mutant $\mathrm{p} 53$ protein but not when the cells contained a wild-type 533 protein. They showed that cells with a mutant or wild-type p53 protein both incorporated the same levels of drug resulting in extensive hypomethylation in both types of cells. However, the cells with wild-type p53 activated the p53 protein for transcription resulting in a $\mathrm{G}_{2} / \mathrm{M}$ checkpoint (via the cdc25c gene product). The p53 mutant cells failed to activate that checkpoint and divided, resulting in aneuploidy, cell death, and apoptosis. Many more of the p53 wild-type cells survived and divided producing cells, avoiding cell death. This was followed up by the work of Leonova 
A.J. Levine et al.

et al. (2013) who found that p53-deficient cells treated with 5-aza-2-deoxycytodine, but not p53 wild-type cells, induced large levels of RNA transcribed from short, interspersed nuclear elements and transcription of both strands of DNA from near centromeric satellite DNAs consisting of tandem repeats and multiple species of noncoding RNAs. These are the related, repeated RNA sequences first described by Ting and colleagues (2011) in human cancerous cells, but not expressed in normal cells. This is one of the epigenetic alterations observed in cancer cells that permit new RNA species to be transcribed from regions of the genome that are normally kept silent (epigenetic changes). Leonova went on to show that mouse cells expressing these RNA sequences induce a strong apoptosis-inducing interferon response, which kills these cells (Leonova et al. 2013). The tumors survive when they become interferon-resistant. These results were then extended by $\mathrm{Yi}$ et al. (2014), showing that a variety of drugs that alter the states of DNA methylation function kill human and mouse cells with p53 mutations more efficiently than comparable cells with wild-type p53. Similarly, mice that harbor either p53 missense mutations or null mutations die more rapidly and at lower doses of these demethylating drugs than mice with a wild-type p53 gene (Yi et al. 2014) showing that this phenomenon occurs in vivo.

Taken together, these experiments are consistent with the hypothesis that the $\mathrm{p} 53$ protein is central to one of the pathways that responds to changing the epigenetic patterns in cells. Just as DNA damage is a stress that p53 responds to by eliminating clones with that damage, epigenetic changes are a stress that $\mathrm{p} 53$ responds to by preventing propagation of such clones of cells. What could be the mechanisms that inform the p53 protein of epigenetic changes and result in new p53 transcriptional programs? The p53 protein is modified by phosphorylation, methylation, acetylation, ubiquitination, sumoylation, and $\mathrm{N}$-acetyl-glycosylation. Further, many of these protein modifications, performed by the same enzyme activities that regulate and modify chromatin, regulate and modify the p53 protein. Chromatin-modifying activities act as oncogenes or tumor suppressor genes, regulating epigenetic changes in a cell and communicating with a variety of transcription factors. Protein modifications are known to regulate p53 activity and transcriptional programs. The p53 protein is reading the epigenetic state of the cell.

\section{CONCLUSIONS}

The evolutionary origins of the p53 family of transcription factors coincide with their appearance in multicellular organisms among the invertebrates (Belyi et al. 2010). In these cases, the p53 family proteins are localized to the germline and respond to starvation, DNA damage, or other stresses by killing the germ cells and enforcing fidelity on the genome (Belyi et al. 2010). In planarians through fish and amphibians, tissue regeneration via the formation of stem cells begins to use the p53 family of genes to maintain long-term stem cells and initiate differentiation into many cell and tissue types (Belyi et al. 2010; Pearson and Sanchez Alvarado 2010; Yun et al. 2013). Although the vertebrates retained p63 for the surveillance of the female germline, p53 was repurposed for the protection of tissue-specific stem cells in the soma. It is at this point that p53 becomes a tumor suppressor that enforces fidelity with death.

The development of tissue-specific stem cells has created its own Darwinian competition in the host. Hematopoietic stem cells replicate in special niches in the body, and mutations arise that permit a clone derived from these cells to outreplicate its sister stem cells. This selection for a subset of stem-cell clones harboring selected mutations can permit these clones to evolve so as to change their patterns of differentiation. For example, older people often produce more myeloid cells than at younger ages; they can have T-cell or B-cell monoclonalopathies and, at the age of 40 to 45 , they are no longer able to function as donors for bone marrow transplants to other people. Because of the lifetime competition of stem cells for replicative advantages, people in their seventh decade of life often have higher levels of hematopoietic stem cells (as defined by greater numbers of $\mathrm{CD} 34^{+}$cells) 
than they do at birth (but the stem cells are not as efficient at making all of the differentiated cells). Some of these stem-cell mutations form the origins of cancer. A growing body of evidence suggests that the first mutation in a stem cell, often called the gatekeeper mutation, may determine the nature and order of selection of subsequent mutations observed in the cancer (Kinzler and Vogelstein 1996; Kinzler and Vogelstein 1998; Belyi et al. 2010). As we have seen from a review of the literature, the inactivation of the p53 protein, whether from mutation, protein modification, or possibly the selective loss of a functional first transactivation domain, results in the enhanced replication of tissuespecific stem cells. Thus, p53 mutations, like several other different mutations, can enhance the selection of tissue-specific stem-cell clones. In some cases and in some tissue types, an early p53 mutation may increase the size of a clone of stem cells in the population and this may predispose to an early onset of cancers.

There is growing evidence that the maintenance of the long-term stem cell requires some p53-mediated functions. At the same time, the transcriptional program from the first transactivation domain of p53 initiates a differentiation pathway and depletes the stem-cell population. As such, the p53 protein appears to act as a bispecific switch for the stem-cell fate. The reverse of this process of differentiation (dedifferentiation) is also impacted by the p53 protein. To efficiently produce stem cells from a differentiated cell (iPS cells), p53 activity must be turned off. There is growing evidence that the p53 protein enforces fidelity of the epigenetic program; inactivation of the p53 functions enhance alterations in the epigenetic state, whether in forming iPS cells or cancerous cells. As predicted from these speculations, evidence is now appearing that shows that hematopoietic stem and the progenitor cells (or progenitor cells treated with chemotherapy) derived from them in older people harbor p53 mutations at a low $(0.003 \%-0.7 \%$ frequency) but detectable frequency (Bondar and Medzhitov 2010; Marusyk et al. 2010; Welch et al. 2012; Wong et al. 2015). Clones of epithelial cells (derived from stem cells) that make up the lining of the esophagus in people with Barrett's esophagus show diverse p53 mutations in different regions (derived from clones) of the esophagus (Barrett et al. 1999). It may well be the case that somatic p53 mutations in tissue-specific stem cells permit the tissue-specific stem cell to replicate more rapidly, be selected for, and begin the process of carcinogenesis as more mutations accumulate in this enlarged population of stem cells. In these cases, p53 would be an early mutation or a gatekeeper guiding the selection of subsequent mutations. In other tumors, p53 might be a late mutation in the evolution of the cancer providing different properties for carcinogenesis.

In patients with $\mathrm{Li}-$ Fraumeni syndrome, all of developmental and adult life functions with reduced levels and activities of p53. In knockout mice for the p53 gene, all of developmental and adult life functions (before cancer development) in the absence of the p53 protein. Thus, p53 is not essential for stem-cell life and differentiation. But the experiments reviewed here suggest that it modulates stem-cell replication and differentiation and impacts on the probability of epigenetic change or instability. LiFraumeni patients may develop between zero and seven tumors over a lifetime depending on their genetic background (modifiers or suppressors) and/or environmental variables. The tissue-specific tumor types arise at defined ages coinciding with stem-cell activity and tissue replication. The spectra of tumors that are observed are mainly derived from the mesoderm and ectoderm, and rarely from the endoderm. But adult tumors of endodermal origin, derived in individuals without a germline p53 mutation, commonly have somatic p53 mutations. Inherited p53 mutations impact stem cells differently than somatic p53 mutations. The observation that aging carriers of p53 mutations that do not develop cancers over their lifetimes have a lower risk to develop tumors after 70 years or so, than the risk of developing cancer for the general population, indicates that there may be genetic suppressors of p53 mutations and cancers in the population. An example of a suppressor of a p53 mutation could be an overexpression of an enzyme that modifies the 
A.J. Levine et al.

remaining wild-type $\mathrm{p} 53$ protein made from the wild-type allele in the cell resulting in higher activity of the wild-type protein. Understanding how these genes function could be very informative and begin a new path to finding drugs that suppress p53 mutations in stem cells, thus preventing the appearance of cancers derived from those stem cells.

\section{REFERENCES}

${ }^{*}$ Reference is also in this collection.

Al-Hajj M, Wicha MS, Benito-Hernandez A, Morrison SJ, Clarke MF. 2003. Prospective identification of tumorigenic breast cancer cells. Proc Natl Acad Sci 100: 39833988.

Ariffin H, Hainaut P, Puzio-Kuter A, Choong SS, Chan AS, Tolkunov D, Rajagopal G, Kang W, Lim LL, Krishnan S, et al. 2014. Whole-genome sequencing analysis of phenotypic heterogeneity and anticipation in $\mathrm{Li}$-Fraumeni cancer predisposition syndrome. Proc Natl Acad Sci 111: 15497-15501.

Armstrong JF, Kaufman MH, Harrison DJ, Clarke AR. 1995. High-frequency developmental abnormalities in p53-deficient mice. Curr Biol 5: 931-936.

Bao X, Wu H, Zhu X, Guo X, Hutchins P, Luo Z, Song H, Chen Y, Lai K, Yin M, et al. 2015. The p53-induced lincRNA-p21 derails somatic cell reprogramming by sustaining $\mathrm{H} 3 \mathrm{~K} 9 \mathrm{me} 3$ and $\mathrm{CpG}$ methylation at pluripotency gene promoters. Cell Res 25: 80-92.

Barker N, van Es JH, Kuipers J, Kujala P, van den Born M, Cozijnsen M, Haegebarth A, Korving J, Begthel H, Peters PJ, et al. 2007. Identification of stem cells in small intestine and colon by marker gene Lgr5. Nature 449: $1003-$ 1007.

Barker N, Huch M, Kujala P, van de Wetering M, Snippert HJ, van Es JH, Sato T, Stange DE, Begthel H, van den Born M, et al. 2010. Lgr5 ${ }^{+v e}$ stem cells drive self-renewal in the stomach and build long-lived gastric units in vitro. Cell Stem Cell 6: 25-36.

Barrett MT, Sanchez CA, Prevo LJ, Wong DJ, Galipeau PC, Paulson TG, Rabinovitch PS, Reid BJ. 1999. Evolution of neoplastic cell lineages in Barrett oesophagus. Nat Genet 22: $106-109$.

Belyi VA, Ak P, Markert E, Wang H, Hu W, Puzio-Kuter A, Levine AJ. 2010. The origins and evolution of the p53 family of genes. Cold Spring Harb Perspect Biol 2: a001198.

Boj SF, Hwang CI, Baker LA, Chio II, Engle DD, Corbo V, Jager M, Ponz-Sarvise M, Tiriac H, Spector MS, et al. 2015. Organoid models of human and mouse ductal pancreatic cancer. Cell 160: 324-338.

Bondar T, Medzhitov R. 2010. p53-mediated hematopoietic stem and progenitor cell competition. Cell Stem Cell 6: 309-322.

Bourdon JC, Fernandes K, Murray-Zmijewski F, Liu G, Diot A, Xirodimas DP, Saville MK, Lane DP. 2005. p53 iso- forms can regulate p53 transcriptional activity. Genes Dev 19: 2122-2137.

Collins AT, Berry PA, Hyde C, Stower MJ, Maitland NJ. 2005. Prospective identification of tumorigenic prostate cancer stem cells. Cancer Res 65: 10946-10951.

Conradt B, Horvitz HR. 1998. The C. elegans protein EGL-1 is required for programmed cell death and interacts with the Bcl-2-like protein CED-9. Cell 93: 519-529.

Courtois S, Caron de Fromentel C, Hainaut P. 2004. p53 protein variants: Structural and functional similarities with p63 and p73 isoforms. Oncogene 23: 631638.

de Lau W, Peng WC, Gros P, Clevers H. 2014. The Rspondin/Lgr5/Rnf43 module: Regulator of Wnt signal strength. Genes Dev 28: 305-316.

Derry WB, Putzke AP, Rothman JH. 2001. Caenorhabditis elegans p53: Role in apoptosis, meiosis, and stress resistance. Science 294: 591-595.

Donehower LA, Harvey M, Slagle BL, McArthur MJ, Montgomery CA Jr, Butel JS, Bradley A. 1992. Mice deficient for p53 are developmentally normal but susceptible to spontaneous tumours. Nature 356: 215-221.

Dudgeon C, Chan C, Kang W, Sun Y, Emerson R, Robins H, Levine AJ. 2014. The evolution of thymic lymphomas in p53 knockout mice. Genes Dev 28: 2613-2620.

Dumay A, Feugeas JP, Wittmer E, Lehmann-Che J, Bertheau P, Espie M, Plassa LF, Cottu P, Marty M, Andre F, et al. 2013. Distinct tumor protein p53 mutants in breast cancer subgroups. Int J Cancer 132: 1227-1231.

Gao D, Vela I, Sboner A, Iaquinta PJ, Karthaus WR, Gopalan A, Dowling C, Wanjala JN, Undvall EA, Arora VK, et al. 2014. Organoid cultures derived from patients with advanced prostate cancer. Cell 159: 176-187.

Ghosh A, Stewart D, Matlashewski G. 2004. Regulation of human p53 activity and cell localization by alternative splicing. Mol Cell Biol 24: 7987-7997.

Gregorieff A, Clevers H. 2010. In situ hybridization to identify gut stem cells. Curr Protoc Stem Cell Biol doi: 10.1002/9780470151808.sc02f01s34.

Gurdon JB. 1973. Nuclear transplantation and regulation of cell processes. Br Med Bull 29: 259-263.

Haoudi A, Semmes OJ, Mason JM, Cannon RE. 2004. Retrotransposition-competent human LINE-1 induces apoptosis in cancer cells with intact p53. J Biomed Biotechnol 2004: 185-194.

Harris CR, Normart R, Yang Q, Stevenson E, Haffty BG, Ganesan S, Cordon-Cardo C, Levine AJ, Tang LH. 2010. Association of nuclear localization of a long interspersed nuclear element-1 protein in breast tumors with poor prognostic outcomes. Genes Cancer 1: 115124.

Harvey DM, Levine AJ. 1991. p53 alteration is a common event in the spontaneous immortalization of primary BALB/c murine embryo fibroblasts. Genes Dev 5: 2375-2385.

Havrilesky L, Darcy KM, Hamdan H, Priore RL, Leon J, Bell J, Berchuck A; Gynecologic Oncology Group Study. 2003. Prognostic significance of $p 53$ mutation and p53 overexpression in advanced epithelial ovarian cancer: A Gynecologic Oncology Group Study. J Clin Oncol 21: 3814-3825. 
p53 in Stem-Cell Biology and Epigenetic Regulation

Hong H, Takahashi K, Ichisaka T, Aoi T, Kanagawa O, Nakagawa M, Okita K, Yamanaka S. 2009. Suppression of induced pluripotent stem cell generation by the $\mathrm{p} 53-\mathrm{p} 21$ pathway. Nature 460: 1132-1135.

Huch M, Bonfanti P, Boj SF, Sato T, Loomans CJ, van de Wetering M, Sojoodi M, Li VS, Schuijers J, Gracanin A, et al. 2013a. Unlimited in vitro expansion of adult bipotent pancreas progenitors through the Lgr5/R-spondin axis. EMBO J 32: 2708-2721.

Huch M, Dorrell C, Boj SF, van Es JH, Li VS, van de Wetering M, Sato T, Hamer K, Sasaki N, Finegold MJ, et al. 2013b. In vitro expansion of single $\mathrm{Lgr}^{+}$liver stem cells induced by Wnt-driven regeneration. Nature 494: 247-250.

Huch M, Gehart H, van Boxtel R, Hamer K, Blokzijl F, Verstegen MM, Ellis E, van Wenum M, Fuchs SA, de Ligt J, et al. 2015. Long-term culture of genome-stable bipotent stem cells from adult human liver. Cell 160: 299-312.

Itzkovitz S, Lyubimova A, Blat IC, Maynard M, van Es J, Lees J, Jacks T, Clevers H, van Oudenaarden A. 2012. Singlemolecule transcript counting of stem-cell markers in the mouse intestine. Nat Cell Biol 14: 106-114.

Jackson-Grusby L, Beard C, Possemato R, Tudor M, Fambrough D, Csankovszki G, Dausman J, Lee P, Wilson C, Lander E, et al. 2001. Loss of genomic methylation causes p53-dependent apoptosis and epigenetic deregulation. Nat Genet 27: 31-39.

Jain AK, Allton K, Iacovino M, Mahen E, Milczarek RJ, Zwaka TP, Kyba M, Barton MC. 2012. p53 regulates cell cycle and microRNAs to promote differentiation of human embryonic stem cells. PLoS Biol 10: e1001268.

Jonkers J, Meuwissen R, van der Gulden H, Peterse H, van der Valk M, Berns A. 2001. Synergistic tumor suppressor activity of BRCA2 and p53 in a conditional mouse model for breast cancer. Nat Genet 29: 418-425.

Kao CY, Nomata K, Oakley CS, Welsch CW, Chang CC. 1995. Two types of normal human breast epithelial cells derived from reduction mammoplasty: Phenotypic characterization and response to SV40 transfection. Carcinogenesis 16: 531-538.

Karthaus WR, Iaquinta PJ, Drost J, Gracanin A, van Boxtel R, Wongvipat J, Dowling CM, Gao D, Begthel H, Sachs N, et al. 2014. Identification of multipotent luminal progenitor cells in human prostate organoid cultures. Cell 159: $163-175$.

Kawamura T, Suzuki J, Wang YV, Menendez S, Morera LB, Raya A, Wahl GM, Izpisua Belmonte JC. 2009. Linking the p53 tumour suppressor pathway to somatic cell reprogramming. Nature 460: 1140-1144.

Kinzler KW, Vogelstein B. 1996. Lessons from hereditary colorectal cancer. Cell 87: 159-170.

Kinzler KW, Vogelstein B. 1998. Landscaping the cancer terrain. Science 280: 1036-1037.

Kleinsmith LJ, Pierce GB Jr. 1964. Multipotentiality of single embryonal carcinoma cells. Cancer Res 24: 1544-1551.

Lawrence MS, Stojanov P, Polak P, Kryukov GV, Cibulskis K, Sivachenko A, Carter SL, Stewart C, Mermel CH, Roberts SA, et al. 2013. Mutational heterogeneity in cancer and the search for new cancer-associated genes. Nature 499: 214-218.
Lee DF, Su J, Ang YS, Carvajal-Vergara X, Mulero-Navarro S, Pereira CF, Gingold J, Wang HL, Zhao R, Sevilla A, et al. 2012. Regulation of embryonic and induced pluripotency by aurora kinase-p53 signaling. Cell Stem Cell 11: 179194.

Leonova KI, Brodsky L, Lipchick B, Pal M, Novototskaya L, Chenchik AA, Sen GC, Komarova EA, Gudkov AV. 2013. p53 cooperates with DNA methylation and a suicidal interferon response to maintain epigenetic silencing of repeats and noncoding RNAs. Proc Natl Acad Sci 110: E89-E98.

Li C, Heidt DG, Dalerba P, Burant CF, Zhang L, Adsay V, Wicha M, Clarke MF, Simeone DM. 2007. Identification of pancreatic cancer stem cells. Cancer Res 67: 10301037.

Li H, Collado M, Villasante A, Strati K, Ortega S, Canamero M, Blasco MA, Serrano M. 2009. The Ink4/Arf locus is a barrier for iPS cell reprogramming. Nature 460: 11361139.

Lin J, Chen J, Elenbaas B, Levine AJ. 1994a. Several hydrophobic amino acids in the p53 amino-terminal domain are required for transcriptional activation, binding to $\mathrm{mdm}-2$ and the adenovirus $5 \mathrm{E} 1 \mathrm{~B} 55-\mathrm{kD}$ protein. Genes Dev 8: 1235-1246.

Lin J, Wu X, Chen J, Chang A, Levine AJ. 1994b. Functions of the 533 protein in growth regulation and tumor suppression. Cold Spring Harb Symp Quant Biol 59: 215223.

Lutzker SG, Levine AJ. 1996. A functionally inactive p53 protein in teratocarcinoma cells is activated by either DNA damage or cellular differentiation. Nat Med 2: 804-810.

Marion RM, Strati K, Li H, Murga M, Blanco R, Ortega S, Fernandez-Capetillo O, Serrano M, Blasco MA. 2009. A p53-mediated DNA damage response limits reprogramming to ensure iPS cell genomic integrity. Nature 460: $1149-1153$.

Markert EK, Mizuno H, Vazquez A, Levine AJ. 2011. Molecular classification of prostate cancer using curated expression signatures. Proc Natl Acad Sci 108: 2127621281.

Marusyk A, Porter CC, Zaberezhnyy V, DeGregori J. 2010. Irradiation selects for p53-deficient hematopoietic progenitors. PLoS Biol 8: e1000324.

Mizuno H, Spike BT, Wahl GM, Levine AJ. 2010. Inactivation of p53 in breast cancers correlates with stem cell transcriptional signatures. Proc Natl Acad Sci 107: 22745-22750.

Muller AJ, Teresky AK, Levine AJ. 2000. A male germ cell tumor-susceptibility-determining locus, pgctl, identified on murine chromosome 13. Proc Natl Acad Sci 97: 8421-8426.

Nieto M, Samper E, Fraga MF, Gonzalez de Buitrago G, Esteller M, Serrano M. 2004. The absence of p53 is critical for the induction of apoptosis by 5 -aza- $2^{\prime}$-deoxycytidine. Oncogene 23: 735-743.

Noutsopoulos D, Markopoulos G, Vartholomatos G, Kolettas E, Kolaitis N, Tzavaras T. 2010. VL30 retrotransposition signals activation of a caspase-independent and p53dependent death pathway associated with mitochondrial and lysosomal damage. Cell Res 20: 553-562. 
A.J. Levine et al.

O'Brien CA, Pollett A, Gallinger S, Dick JE. 2007. A human colon cancer cell capable of initiating tumour growth in immunodeficient mice. Nature 445: 106-110.

Olivier M, Hollstein M, Hainaut P. 2010. TP53 mutations in human cancers: Origins, consequences, and clinical use. Cold Spring Harb Perspect Biol 2: a001008.

Ortt K, Sinha S. 2006. Derivation of the consensus DNAbinding sequence for p63 reveals unique requirements that are distinct from p53. FEBS Lett 580: 4544-4550.

Pankow S, Bamberger C. 2007. The p53 tumor suppressorlike protein nvp63 mediates selective germ cell death in the sea anemone Nematostella vectensis. PLoS ONE 2: e782.

Pearson BJ, Sanchez Alvarado A. 2010. A planarian p53 homolog regulates proliferation and self-renewal in adult stem cell lineages. Development 137: 213-221.

Petersen OW, Ronnov-Jessen L, Howlett AR, Bissell MJ 1992. Interaction with basement membrane serves to rapidly distinguish growth and differentiation pattern of normal and malignant human breast epithelial cells. Proc Natl Acad Sci 89: 9064-9068.

Puzio-Kuter AM, Levine AJ. 2009. Stem cell biology meets p53. Nat Biotechnol 27: 914-915.

* Raj N, Attardi LD. 2016. The transactivation domains of the p53 protein. Cold Spring Harb Perspect Med doi: 10.1101/ cshperspect.a026047.

Ricci-Vitiani L, Lombardi DG, Pilozzi E, Biffoni M, Todaro M, Peschle C, De Maria R. 2007. Identification and expansion of human colon-cancer-initiating cells. Nature 445: 111-115.

Sah VP, Attardi LD, Mulligan GJ, Williams BO, Bronson RT Jacks T. 1995. A subset of p53-deficient embryos exhibit exencephaly. Nat Genet 10: 175-180.

Sato T, Vries RG, Snippert HJ, van de Wetering M, Barker N, Stange DE, van Es JH, Abo A, Kujala P, Peters PJ, et al. 2009. Single Lgr5 stem cells build crypt-villus structures in vitro without a mesenchymal niche. Nature 459: $262-$ 265.

Sato T, Stange DE, Ferrante M, Vries RG, Van Es JH, Van den Brink S, Van Houdt WJ, Pronk A, Van Gorp J, Siersema PD, et al. 2011. Long-term expansion of epithelial organoids from human colon, adenoma, adenocarcinoma, and Barrett's epithelium. Gastroenterology 141: $1762-$ 1772.

Schatton T, Murphy GF, Frank NY, Yamaura K, Waaga-Gasser AM, Gasser M, Zhan Q, Jordan S, Duncan LM, Weishaupt $\mathrm{C}$, et al. 2008. Identification of cells initiating human melanomas. Nature 451: 345-349.

Schuijers J, Clevers H. 2012. Adult mammalian stem cells: The role of Wnt, Lgr5 and R-spondins. EMBO J 31: 2685-2696.

Schumacher B, Schertel C, Wittenburg N, Tuck S, Mitani S, Gartner A, Conradt B, Shaham S. 2005. C. elegans ced-13 can promote apoptosis and is induced in response to DNA damage. Cell Death Differ 12: 153-161.

Smeenk L, van Heeringen SJ, Koeppel M, van Driel MA, Bartels SJ, Akkers RC, Denissov S, Stunnenberg HG, Lohrum M. 2008. Characterization of genome-wide p53binding sites upon stress response. Nucleic Acids Res 36: 3639-3654.
Stevens LC, Varnum DS. 1974. The development of teratomas from parthenogenetically activated ovarian mouse eggs. Dev Biol 37: 369-380.

Stingl J, Eaves CJ, Zandieh I, Emerman JT. 2001. Characterization of bipotent mammary epithelial progenitor cells in normal adult human breast tissue. Breast Cancer Res Treat 67: 93-109.

Suh EK, Yang A, Kettenbach A, Bamberger C, Michaelis AH, Zhu Z, Elvin JA, Bronson RT, Crum CP, McKeon F. 2006 p63 protects the female germ line during meiotic arrest. Nature 444: 624-628.

Sun W, Kang KS, Morita I, Trosko JE, Chang CC. 1999. High susceptibility of a human breast epithelial cell type with stem cell characteristics to telomerase activation and immortalization. Cancer Res 59: 6118-6123.

Takahashi K, Tanabe K, Ohnuki M, Narita M, Ichisaka T, Tomoda K, Yamanaka S. 2007. Induction of pluripotent stem cells from adult human fibroblasts by defined factors. Cell 131: 861-872.

Tinat J, Bougeard G, Baert-Desurmont S, Vasseur S, Martin C, Bouvignies E, Caron O, Bressac-de Paillerets B, Berthet P, Dugast C, et al. 2009. 2009 version of the Chompret criteria for Li Fraumeni syndrome. J Clin Oncol 27: e108e109; author reply e110.

Ting DT, Lipson D, Paul S, Brannigan BW, Akhavanfard S, Coffman EJ, Contino G, Deshpande V, Iafrate AJ, Letovsky S, et al. 2011. Aberrant overexpression of satellite repeats in pancreatic and other epithelial cancers. Science 331: 593-596.

Tozluoglu M, Karaca E, Haliloglu T, Nussinov R. 2008. Cataloging and organizing p73 interactions in cell cycle arrest and apoptosis. Nucleic Acids Res 36: 5033-5049.

Trkova M, Hladikova M, Kasal P, Goetz P, Sedlacek Z. 2002. Is there anticipation in the age at onset of cancer in families with Li-Fraumeni syndrome? J Hum Genet 47: 381386.

Tumbar T, Guasch G, Greco V, Blanpain C, Lowry WE, Rendl M, Fuchs E. 2004. Defining the epithelial stem cell niche in skin. Science 303: 359-363.

Turner N, Moretti E, Siclari O, Migliaccio I, Santarpia L, D'Incalci M, Piccolo S, Veronesi A, Zambelli A, Del Sal G, et al. 2013. Targeting triple negative breast cancer: Is p53 the answer? Cancer Treat Rev 39: 541-550.

Ungewitter E, Scrable H. 2010. $\Delta 40$ p53 controls the switch from pluripotency to differentiation by regulating IGF signaling in ESCs. Genes Dev 24: 2408-2419.

Vigano MA, Lamartine J, Testoni B, Merico D, Alotto D, Castagnoli C, Robert A, Candi E, Melino G, Gidrol X, et al. 2006. New p63 targets in keratinocytes identified by a genome-wide approach. EMBO J 25: 5105-5116.

Watkins-Chow DE, Pavan WJ. 2008. Genomic copy number and expression variation within the $\mathrm{C} 57 \mathrm{BL} / 6 \mathrm{~J}$ inbred mouse strain. Genome Res 18: 60-66.

Welch JS, Ley TJ, Link DC, Miller CA, Larson DE, Koboldt DC, Wartman LD, Lamprecht TL, Liu F, Xia J, et al. 2012. The origin and evolution of mutations in acute myeloid leukemia. Cell 150: 264-278.

Wong TN, Ramsingh G, Young AL, Miller CA, Touma W, Welch JS, Lamprecht TL, Shen D, Hundal J, Fulton RS, et al. 2015. Role of TP53 mutations in the origin and 
p53 in Stem-Cell Biology and Epigenetic Regulation

evolution of therapy-related acute myeloid leukaemia. Nature 518: 552-555.

Xu X, Qiao W, Linke SP, Cao L, Li WM, Furth PA, Harris CC, Deng CX. 2001. Genetic interactions between tumor suppressors Brcal and p53 in apoptosis, cell cycle and tumorigenesis. Nat Genet 28: 266-271.

Yi L, Lu C, Hu W, Sun Y, Levine AJ. 2012. Multiple roles of p53-related pathways in somatic cell reprogram- ming and stem cell differentiation. Cancer Res 72: 56355645.

Yi L, Sun Y, Levine A. 2014. Selected drugs that inhibit DNA methylation can preferentially kill p53 deficient cells. Oncotarget 5: 8924-8936.

Yun MH, Gates PB, Brockes JP. 2013. Regulation of p53 is critical for vertebrate limb regeneration. Proc Natl Acad Sci 110: 17392-17397. 


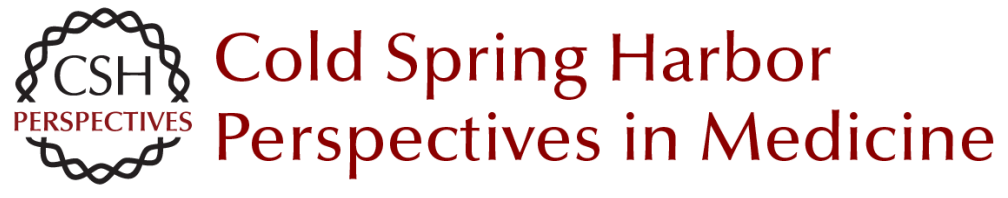

\title{
The Role of the p53 Protein in Stem-Cell Biology and Epigenetic Regulation
}

\author{
Arnold J. Levine, Anna M. Puzio-Kuter, Chang S. Chan and Pierre Hainaut
}

Cold Spring Harb Perspect Med 2016; doi: 10.1101/cshperspect.a026153 originally published online June 28, 2016

\section{Subject Collection The p53 Protein}

\section{Targeting the MDM2-p53 Protein-Protein Interaction for New Cancer Therapy: Progress and Challenges Shaomeng Wang, Yujun Zhao, Angelo Aguilar, et al.}

Structural Evolution and Dynamics of the p53 Proteins

Giovanni Chillemi, Sebastian Kehrloesser, Francesca Bernassola, et al.

\section{Exploiting the p53 Pathway for Therapy} Chit Fang Cheok and David Philip Lane

The Regulation of Cellular Functions by the p53 Protein: Cellular Senescence Crystal A. Tonnessen-Murray, Guillermina Lozano and James $G$. Jackson

The Transactivation Domains of the p53 Protein Nitin Raj and Laura D. Attardi

The Evolution of the Ribosomal Protein-MDM2p53 Pathway

Chad Deisenroth, Derek A. Franklin and Yanping Zhang

Somatic TP53 Mutations in the Era of Genome Sequencing Pierre Hainaut and Gerd P. Pfeifer

The Paradox of p53: What, How, and Why? Yael Aylon and Moshe Oren
Control of Cellular Aging, Tissue Function, and Cancer by p53 Downstream of Telomeres Caitlin M. Roake and Steven E. Artandi

Inherited TP53 Mutations and the Li -Fraumeni Syndrome

Tanya Guha and David Malkin

\section{TP53 Mutations in Hypodiploid Acute Lymphoblastic Leukemia \\ Evan Q. Comeaux and Charles G. Mullighan \\ Transcriptional Regulation by Wild-Type and \\ Cancer-Related Mutant Forms of p53 \\ Neil T. Pfister and Carol Prives}

The Inherited p53 Mutation in the Brazilian

Population

Maria Isabel Achatz and Gerard P. Zambetti

TP53 Mutations in Breast and Ovarian Cancer Laxmi Silwal-Pandit, Anita Langerød and Anne-Lise Børresen-Dale

p53 and the Carcinogenicity of Chronic Inflammation

Andrei V. Gudkov and Elena A. Komarova

Oncogenic Mutant p53 Gain of Function

Nourishes the Vicious Cycle of Tumor

Development and Cancer Stem-Cell Formation

Yoav Shetzer, Alina Molchadsky and Varda Rotter

For additional articles in this collection, see http://perspectivesinmedicine.cshlp.org/cgi/collection/ 